\title{
Morphological, thermal, and thermomechanical properties of cellulose nanocrystals reinforced polylactide/poly [(butylene succinate)-co-adipate] blend composite foams
}

\author{
Mpho Phillip Motloung ${ }^{1,2}$, Simphiwe Zungu', Vincent Ojijo ${ }^{1,2}$, Jayita Bandyopadhyay ${ }^{1}$ and Suprakas Sinha Ray ${ }^{1,2^{*}}$ (D)
}

\begin{abstract}
This study examines the influence of cellulose nanocrystal (CN) particles on the morphological, thermal, and thermo-mechanical properties of polylactide (PLA)/poly [(butylene succinate)-co-adipate] (PBSA) blend foams prepared by casting and particulate leaching method using fructose as porogen particles. The morphological analysis showed an interconnected open-cell structure, with porosity above $80 \%$. The crystallinity of the prepared foams was disrupted by the inclusion of CN particles as observed from XRD analyses, which showed a decrease in PLA crystal peak intensity. With regards to neat blend foam, the onset thermal degradation increased with the addition of CN particles, which also increased the thermal stability at 50\% weight loss. Furthermore, CN acted as a reinforcing agent in improving the stiffness of the prepared blend foam. Overall, completely environmentally friendly foams were successfully prepared, as a potential material that can replace the current existing foam materials that pose many environmental concerns. However, there is a need to develop an environmentally friendly processing technique.
\end{abstract}

Keywords: PLA/PBSA blend, Foam morphology, Cellulose nanocrystal, Thermal properties

\section{Introduction}

Since their discovery in the 1930s, polymer foams became important for various applications including packaging because of their light-weight, low density, and low material usage during their preparation compared to unfoamed polymers. To date, polystyrene (PS), polyurethane (PU), and poly (vinyl chloride) (PVC) remain the most widely used polymer foam materials. The most common challenge with these materials is their non-biodegradability in natural environments, as they pose environmental

\footnotetext{
*Correspondence: rsuprakas@csir.co.za; ssinharay@uj.ac.za

${ }^{1}$ Centre for Nanostructures and Advanced Materials, DSI-CSIR

Nanotechnology Innovation Centre, Council for Scientific and Industrial Research, Pretoria 0001, South Africa

${ }^{2}$ Department of Chemical Sciences, University of Johannesburg, Doornfontein 2028, Johannesburg, South Africa
}

concerns such as pollution, which ends up affecting various forms of life [1-4]. As a result, this necessitates the development of polymer foam materials which would at least be able to degrade in natural environments to alleviate the environmental concerns regarding polymers in general. Polylactide (PLA) has received vast attention as a potential biodegradable polymer material that, to some extent, can substitute non-biodegradable polymer foams for a specific type of application such as packaging. Although PLA is desired, it has disadvantages which impede its widespread application. They include slow crystallization and biodegradation rate, poor thermal stability, and brittleness, which results in poor mechanical properties; in particular, low impact- and melt-strength and toughness. The standard strategy to mitigate these shortcomings is
Springer Open

(c) The Author(s). 2020 Open Access This article is licensed under a Creative Commons Attribution 4.0 International License, which permits use, sharing, adaptation, distribution and reproduction in any medium or format, as long as you give appropriate credit to the original author(s) and the source, provide a link to the Creative Commons licence, and indicate if changes were made. The images or other third party material in this article are included in the article's Creative Commons licence, unless indicated otherwise in a credit line to the material. If material is not included in the article's Creative Commons licence and your intended use is not permitted by statutory regulation or exceeds the permitted use, you will need to obtain permission directly from the copyright holder. To view a copy of this licence, visit http://creativecommons.org/licenses/by/4.0/. 
the inclusion of flexible and ductile polymers such as poly[(butylene-succinate)-co-adipate] (PBSA).

PBSA is a biodegradable polymer, which has outstanding properties, including high thermal stability and high impact strength compared to PLA. Moreover, PBSA is susceptible to biodegradation in various environments such as in soil, sludge, and others. Due to its short biodegradation time, it can also enhance the biodegradation rate of PLA, which is very slow [5-10]. Therefore, a blend of PLA with PBSA can result in improved properties of PLA, though this blend is considered immiscible [5]. Addition of filler materials at specific concentrations can result in improved compatibility of the blend matrices. For instance, Ojijo et al. [11] observed improvements in crystallinity and mechanical properties of PLA/ PBSA at $2 \mathrm{wt} . \%$ of clay nanoparticles, which was the optimum amount to obtain compatibility and enhanced properties. The foamability of PLA/PBSA blend and nanocomposites has also been investigated, although to a limited extent. Nofar et al. [6] investigated the foamability of this blend through extrusion foaming. In their case, PBSA was added into PLA to enhance its melt strength, which is also a limiting factor in continuous foaming processes. Most biodegradable polymers, including PLA, suffer low melt strength, which usually results in a cell rupture and cell coalescing during foaming [12, 13]. Pradeep et al. [14] also prepared PLA/PBSAbased foams containing talc using supercritical fluidassisted (SCF) injection molding.

Generally, the addition of fillers into blend systems leads to the improvement of certain properties which blend exhibits. Natural fillers such as cellulose nanoparticles $(\mathrm{CNs})$ have received considerable interest as reinforcing materials and nucleating agents in improving the crystallinity of most polymers because of their environmental friendliness and biodegradability, compared to most inorganic fillers $[15,16]$. In previous reports [17, 18], it was demonstrated that the addition of cellulose is able to improve the soil burial degradation kinetics of PBSA- [17] and PCL-based [18] composites. Consequently, design and developments of biodegradable polymer-based foams containing cellulose particles are of interest. For instance, PLA/CNs foams with porosity greater than $80 \%$ were successfully developed using casting and particulate leaching (CPL) method [19].

CPL is the easiest foaming strategy, which is mostly used to prepare scaffolds in tissue engineering. The advantage of this strategy is that the melt strength of a polymer is not a key issue since the cell morphology is dependent on porogen particles. In this method, a polymer is dissolved in a volatile solvent until a homogeneous mixture is obtained. The porogen particles, which are insoluble in a solvent, are added into a solution, and then cast into a mold whereby a solvent is allowed to evaporate leaving polymer-porogen blend in a mold. The porogen particles are then leached out, leaving porous polymer foam $[19,20]$. In a continuous foam process such as extrusion, the foam morphology is controlled by the second component such as fillers in biphasic systems. Contrarily, in CPL, the foam morphology is dictated by porogen size and concentration [1, 19-22]. As a result, the incorporation of fillers in CPL is expected to reinforce and improve certain foam properties and not influence the cell morphology. Interestingly, Borkotoky et al. [19] observed dependence of pore size on filler (CNs) concentrations in PLA/CNs foams prepared using CPL method and attributed this to nucleating capacity of $\mathrm{CN}$ particles in controlling cell size and density. However, with this strategy, the morphology is expected to be dictated by porogen particles and not filler material.

In the current study, PBSA was incorporated into PLA with the intention of developing blend foams with enhanced properties. One of the advantages of polymer blending is to develop systems with improved properties, which the individual polymers do not exhibit. CPL method was employed to generate foams. $\mathrm{CN}$ particles were also added to reinforce the PLA/PBSA blend. CN is rigid nanofiller material that is environmentally friendly and abundant as it can be obtained from various sources [23]. The effect of both CN and PBSA on the properties of PLA foam was investigated.

\section{Experimental \\ Materials}

PLA (Ingeo ${ }^{\mathrm{m}}$ 4032D grade from NatureWorks LLC, Minnetonka, USA) and poly [(butylene succinate)-coadipate) (PBSA, Bionolle, 3001 from Showa High Polymer, Japan) were used. PLA and PBSA have densities of $1.23 \pm 0.02$ and $1.22 \pm 0.1 \mathrm{~g} / \mathrm{cm}^{3}$, respectively, as determined using the immersion method in RADWAG AS60/220-R2 instrument, according to ISO standard 1183. Spray-dried cellulose nanocrystals $(\mathrm{CN})$ (particle size: $100-230 \mathrm{~nm}$, according to the supplier) was supplied by InnoTech Alberta, Canada. D-Fructose and chloroform (99\%) were purchased from Sigma Aldrich, South Africa.

\section{Foam processing}

The film foams were prepared using CPL method and the compositions are summarized in Table 1. Briefly, PLA and PBSA (ratio, PBSA:PLA 70:30 were dissolved in chloroform $(150 \mathrm{ml})$ for approximately $2 \mathrm{~h}$ under vigorous stirring until a homogeneous mixture is obtained. The porogen substance (fructose with particle size < $100 \mu \mathrm{m}$ ) was added to the polymer solution and mixed further for $1 \mathrm{~h}$ under stirring before casting. For nanocomposites, the $\mathrm{CN}$ particles were added to the blend solution and mixed for $1 \mathrm{~h}$ before addition of porogen 
Table 1 Compositions of the prepared foams

\begin{tabular}{lllll}
\hline Sample & Composition & Blend ratio (PLA:PBSA) & Blend: Fructose & CN-wt.\% \\
\hline PLA & PLA & $100: 0$ & $1: 5$ & - \\
B & PLA/PBSA & $70: 30$ & $1: 5$ & - \\
B-CN3 & PLA/PBSA/CN & $70: 30$ & $1: 5$ & 3 \\
B-CN6 & PLA/PBSA/CN & $70: 30$ & $1: 5$ & 6 \\
PBSA & PBSA & $0: 100$ & $1: 5$ & - \\
\hline
\end{tabular}

particles. The solutions were cast into a mold pan (dimensions: $18 \mathrm{~cm} \times 18 \mathrm{~cm}$ ) and placed in fume-cupboard to allow the solvent to evaporate for overnight. The porogen leaching was achieved by initially adding water inside the molds for $8 \mathrm{~h}$, which allowed the samples to be removed easily from the molds without any damage. After the removal, the samples were then immersed inside water for further $48 \mathrm{~h}$, replacing water at least twice in a day. The prepared film foams were air-dried in fume-cupboard for $24 \mathrm{~h}$.

\section{Characterization and property measurements Characterization}

The chemical structures of the samples were determined using an attenuated total reflectance (ATR) Fourier transform infrared (FTIR) spectroscopy (Perkin-Elmer Spectrum 100 spectrometer). The wavelength ranging from 600 to $4000 \mathrm{~cm}^{-1}$ was used at a resolution of 4 $\mathrm{cm}^{-1}$.

The morphologies of the samples (sputter-coated with carbon) were analyzed using scanning electron microscopy (SEM) (JSM-7500, JEOL, Japan) at an accelerating voltage of $3.0 \mathrm{kV}$.

The crystallinity of the prepared foams and the foam morphological analysis using small-angle-X-ray scattering were evaluated using Anton Paar SAXSess (Anton Paar, Graz, Austria) instrument operated at $40 \mathrm{kV}$ and $50 \mathrm{~mA}$ in line collimation. The radiation used was $\mathrm{CuK}_{\alpha}$ radiation of wavelength $0.154 \mathrm{~nm}$ (PAN Analytical X-ray source, Eindhoven, The Netherlands). The sample exposure time used was $10 \mathrm{~min}$. The radius of curvature of the imaging plate detector and distance sample detector and were and $260 \mathrm{~mm}$ and $260.2 \mathrm{~mm}$, respectively. The samples with dimensions: $2.5 \mathrm{~mm} \times 5 \mathrm{~mm}$ were used for the analysis. The theory behind the SAXS analysis for determination of foam properties; in particular, surfaceper-volume can be found elsewhere [24].

Thermal degradation of the foams was performed using TGA (TGA 5500, USA). Samples weighing approximately $7 \mathrm{mg}$ were heated from 30 to $700{ }^{\circ} \mathrm{C}$ at a heating rate of $10{ }^{\circ} \mathrm{C} / \mathrm{min}$ under nitrogen environment (flow rate $=25 \mathrm{ml} / \mathrm{min}$ ). Thermomechanical properties of the foamed samples were conducted using PerkinElmer DMA 800 analyzer (USA) under dual-cantilever bending mode in the temperature range of $-80{ }^{\circ} \mathrm{C}$ to $100{ }^{\circ} \mathrm{C}$ at a heating rate of $2{ }^{\circ} \mathrm{C} / \mathrm{min}$. The analysis was performed at a frequency of $1 \mathrm{~Hz}$, with a strain amplitude of $0.02 \%$.

\section{Foam morphological properties \\ Density $(\rho)$}

The densities of the prepared foams were determined from the ratio of measured mass to volume of the foam sample. The dimensions (length $\times$ breadth $=20 \times 20 \mathrm{~mm}$ ) and height $(\sim 1.8 \mathrm{~mm})$ were used to calculate the volume of the foams. For each foam material, five specimens were used, and the average was determined.

\section{Void fraction $(\varphi)$}

The void fraction/porosity and expansion ratio $(\beta)$ of the materials were determined according to Eqs. 1 and 2, respectively [19, 24].

$$
\phi=\left(\rho_{\text {unfoamed }}-\rho_{\text {foamed }}\right) /\left(\rho_{\text {unfoamed }}-\rho_{p}\right)
$$

Where $\rho_{p}$ is the density of pore space, which is approximately 0

$$
\beta=\rho_{\text {unfoamed }} / \rho_{\text {foamed }}
$$

\section{Results and discussion \\ Leaching test}

The leaching of fructose in all samples was confirmed with Barfoed test experiment (Figure S1, Supporting Information). This is a qualitative test used to determine the presence of monosaccharides in solutions [25]. In this test, a Barfoed reagent (a mixture of copper (II) acetate and acetic acid) is mixed with a solution containing monosaccharides (e.g. fructose), which forms a reddish/brownish copper (I) oxide $\left(\mathrm{Cu}_{2} \mathrm{O}\right)$ precipitate. Copper (II) acetate is reduced to $\mathrm{Cu}_{2} \mathrm{O}$ according to chemical Eq. 3:

$$
\begin{aligned}
& \mathrm{RCHO}+2 \mathrm{Cu}^{2+}+2 \mathrm{H}_{2} \mathrm{O} \rightarrow \mathrm{RCOOH} \\
& +\mathrm{Cu}_{2} \mathrm{O} \downarrow(\text { red/brown })+4 \mathrm{H}^{+}
\end{aligned}
$$

Briefly, five sample specimen (dimensions: $5 \mathrm{~mm} \times 10$ $\mathrm{mm}$ ) were cut from different spots and immersed in deionized water $(20 \mathrm{ml})$ for $24 \mathrm{~h}$ under stirring. A solution of fructose in water and neat water were used as controls. The sample solutions $(1 \mathrm{~mL})$ were taken for the 
analysis. The Barfoed reagent used was prepared by mixing $0.33 \mathrm{M}$ of copper (II) acetate solution with 4 drops of glacial acetic acid. About $0.2 \mathrm{~mL}$ of the prepared Barfoed reagent was added into sample solutions and then heated in boiling water for $5 \mathrm{~min}$. The formation of the reddish/brownish precipitate in a control sample containing fructose indicates the presence of monosaccharide in a solution, whereas the distilled water did not form a reddish precipitate. However, in the sample solutions, the reddish/brownish precipitate was also not observed, indicating the absence of fructose in water. However, it is worth noting that a certain fraction of porogen particles might be trapped within the polymer; therefore, other techniques, including FTIR were also exercised to confirm successful leaching of fructose.

\section{Chemical structure}

The chemical structures of the prepared foams are shown in Fig. 1. The influence of chloroform on the structure of neat matrices was also examined, and the results indicated no effect on their chemical structures (Figure S2, Supporting Information). Neat PLA foam is characterized by pronounced carbonyl $(-\mathrm{C}=\mathrm{O})$ peak at $1755 \mathrm{~cm}^{-1}$ [5]. In the blend and nanocomposite foams, only overlapping of $(-\mathrm{C}=\mathrm{O})$ groups from both PLA and PBSA was noticed. The characteristic peaks associated with $\mathrm{CN}$ were also not noticed in the nanocomposite foams because of the encapsulation of $\mathrm{CN}$ within polymer matrices. Moreover, neither chemical groups associated with fructose on the surfaces of the foams were

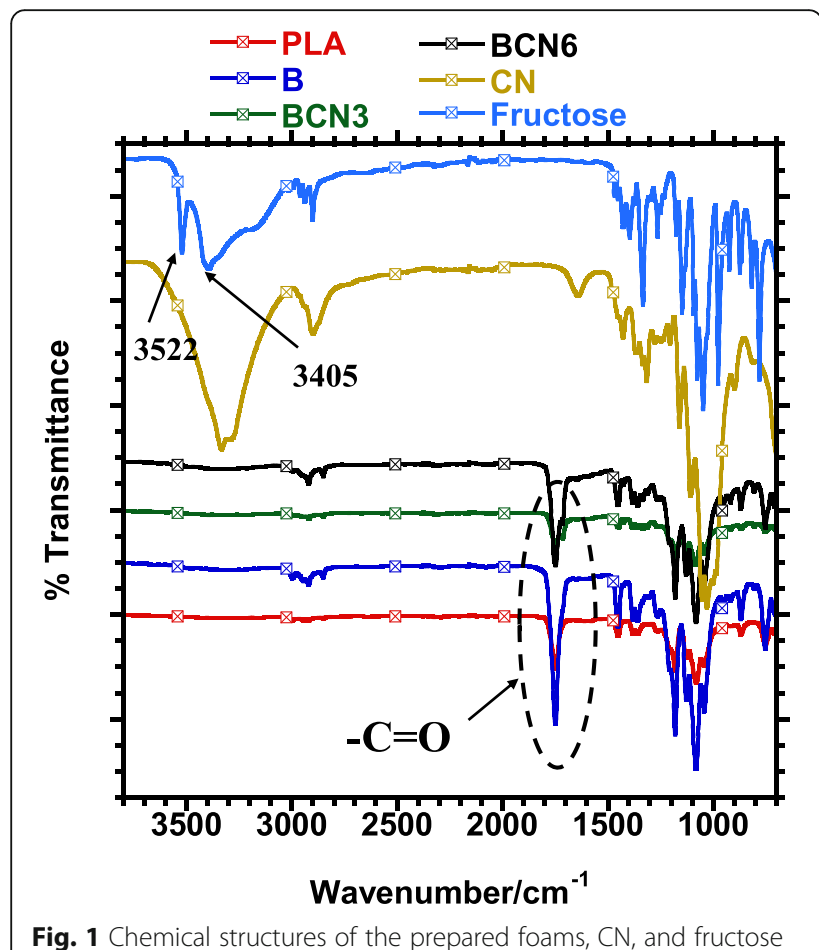

Fig. 1 Chemical structures of the prepared foams, CN, and fructose noticed; that is, the characteristic peaks at 3522, and $3388 \mathrm{~cm}^{-1}$ associated with stretching vibrations of hydroxyl groups $(-\mathrm{OH})$ groups [26]. The chemical groups associated with fructose particles were not observed, suggesting successful leaching of porogen particles.

\section{Foam morphologies}

A solid cellular material consists of an interconnected network of solid struts, whereby a cell is an unoccupied space delimited by solid boundaries [27]. The surface morphologies of the prepared foams are shown in Fig. 2 (low-magnification SEM images are reported in Figure S3, Supporting Information), and the morphological characteristics are summarized in Table 2. It can be noticed that all foams exhibited irregular, interconnected open cell structure with high porosity $(>80 \%)$ (Table 2 ).

Generally, nanoparticles act as nucleating agents and contribute to the formation of well-controlled morphology of the foams [28]. However, in this case, the cell morphology is dictated by the porogen particles. Therefore, ideally, the foam morphological properties should not differ due to the same amount of porogen. The porosity of the prepared foams is in the same range, thanks to the same amount of porogen particles added. Furthermore, it is also discernible from the images that the cell size of the prepared foams is not uniform throughout the foams. However, the expectation was that the cell size would be the same because of the same size of porogen particles. The variation in the cell size can be due to interconnected network of porogens, which generate different sizes during leaching; that is, a pore can be formed by two or more porogens in contact with each other, while others can only be formed by a single porogen particle.

The morphology of the foams was further examined using SAXS. Combination of SAXS and small-angle neutron scattering (SANS) has been used to investigate the morphological characteristics of a filtration membrane made of mixed cellulose ester [24]. In this study, the porosity of the material was determined based on the surface-per-volume $(\mathrm{SpV})$ of the materials, which was extracted from the unified Porod fit in Porod region, as shown in Fig. 3a and a'. From the summarised results in Table 3, the SpV decreased in order PLA'B'B-CN3'B$\mathrm{CN} 6$, indicating a reduction in porosity of the materials, and this corroborates a slight decrease in foam density. The pore chord length $\left(l_{p}\right)$ which gives average pore size and solid chord length $\left(l_{s}\right)$ which provides an average skeletal size were also extracted from Porod analysis according to Eqs. 4 and 5, respectively [24]. The solid chord length $\left(l_{s}\right)$ showed an increasing trend due to a decrease in porosity (SEM analysis), with respect to neat PLA foam. The $l_{p}$ values in Table 3 were compared with the average pore size from the SEM images. The cell size 

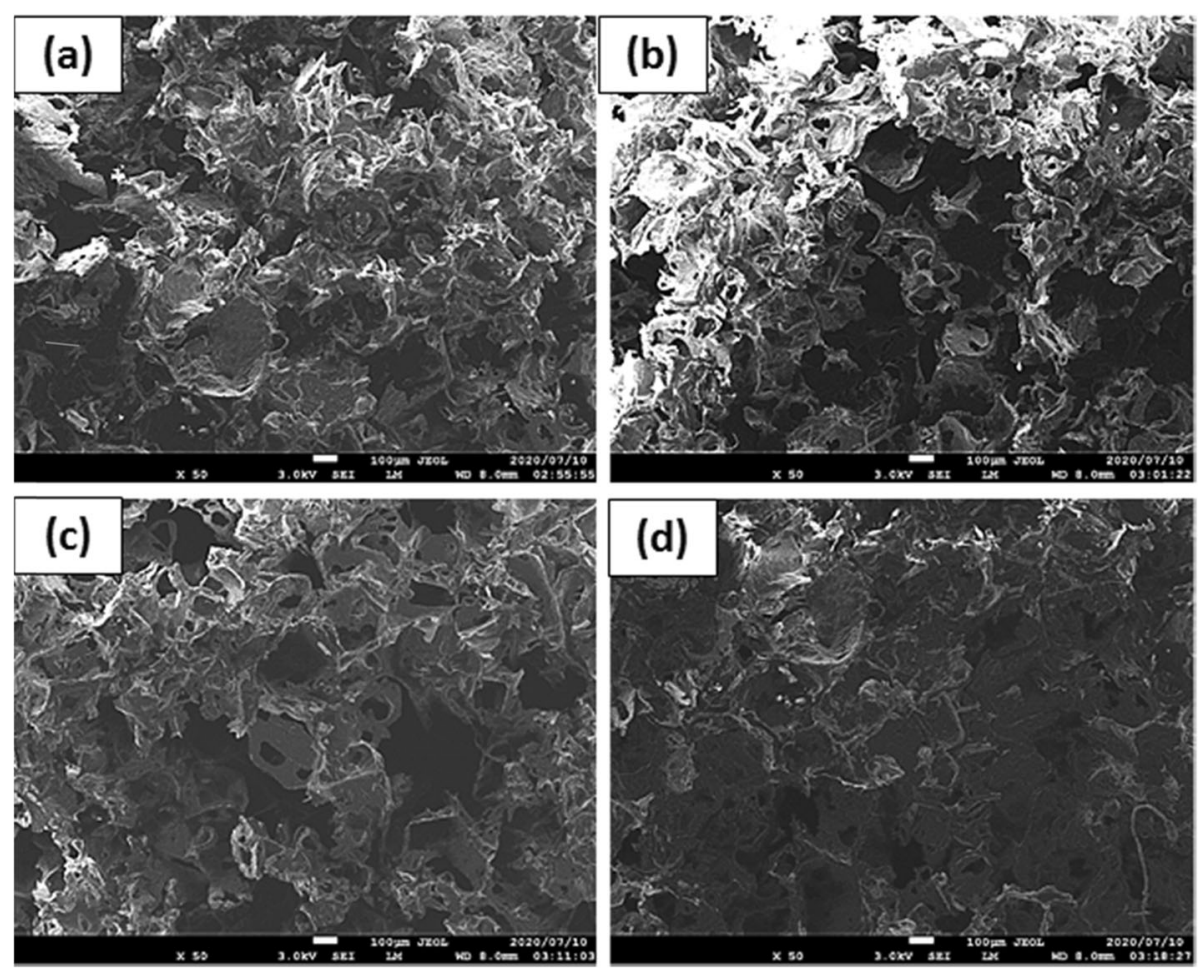

Fig. 2 Surface morphologies of the prepared foams (a) neat PLA, (b) B, (c) B-CN3, and (d) B-CN6

determined from SAXS and SEM were extremely different, and the reason can be that the analysis from SAXS is indirect as compared to direct analysis from SEM [29]. However, the observed trend of $l_{s}$ is in agreement with the SEM results, which showed a slight decrease in the porosity of the foams. The Porod length $(l)$, which is the harmonic mean of both strut and solid chords (Eq. 6) was compared with Porod length from Guinier $\left(l_{G}\right)$ using the radius of gyration $\mathrm{Rg}$ (Eq. 7) determined from unified Guinier fit in Guinier region at low scattering vector as shown in Fig. 3a" [24, 30]. The Debye-AndersonBrumberger model was used to determine a Porod length from Guinier analysis. For all the samples, the $l$ and $l_{G}$ were more or less the same $(\sim 0.0040 \mu \mathrm{m})$, implying that Debye-Anderson-Brumberger model was a good approximation for the prepared foams.

$$
\begin{aligned}
& \left\langle l_{p}\right\rangle=4 \phi_{p} / S p V \\
& \left\langle l_{s}\right\rangle=4 \phi_{s} / S p V
\end{aligned}
$$

Table 2 The morphological properties of the prepared foams

\begin{tabular}{llll}
\hline Sample & $\boldsymbol{\rho}_{\text {foam }}\left(\mathbf{g} / \mathbf{c m}^{\mathbf{3}}\right)$ & Expansion ratio $(\boldsymbol{\beta})$ & Void Fraction $(\boldsymbol{\varphi})(\%)$ \\
\hline PLA & $0.18 \pm 0.0$ & $6.69 \pm 0.12$ & 85.05 \\
B & $0.19 \pm 0.01$ & $6.53 \pm 0.30$ & 84.66 \\
B-CN3 & $0.19 \pm 0.01$ & $6.44 \pm 0.35$ & 84.43 \\
B-CN6 & $0.21 \pm 0.01$ & $5.81 \pm 0.27$ & 82.75 \\
\hline
\end{tabular}

$$
\begin{aligned}
& \langle l\rangle=4 \phi_{s} \phi_{p} / S p V \\
& \left\langle l_{G}\right\rangle=\mathrm{R}_{\mathrm{G}} / \sqrt{6}
\end{aligned}
$$

Where $\mathrm{SpV}$ is surface-per-volume; $\mathrm{Rg}$ is the radius of gyration; $\left\langle l_{s}\right\rangle$ is solid chord length; $\left\langle l_{p}\right\rangle$ is pore chord length; $\left\langle l_{G}\right\rangle$ is Porod length determined from Guinier. $\phi_{s}$ and $\phi_{p}$ are strut volume fraction and pore volume fraction, respectively.

\section{Crystalline structure}

The crystalline structures of the prepared foams were evaluated from wide-angle scattering of SAXS experiment, and the results are shown in Fig. 4. PBSA crystalline structure was not affected by the solvent as it remained unchanged, while the only noticeable change was observed in PLA after solvent processing (Figure S4, Supporting Information). The crystalline structure of the $\mathrm{CN}$ is shown in Figure S5 of Supporting Information. Generally, PLA crystallizes in $\alpha, \beta$, and $\gamma$ forms, and its crystallization is influenced by the type of processing it undergoes. In this case, PLA and chloroform have stronger interactions, which induce crystallization of PLA after solvent vaporization [31]. Hence, three distinct crystalline peaks were observed at $15.05^{\circ}, 16.85^{\circ}$, and $19.25^{\circ}$ in a solvent-processed PLA, which are attributed to (110), (110)/(200), and (203) planes of PLA $\alpha$ form, 

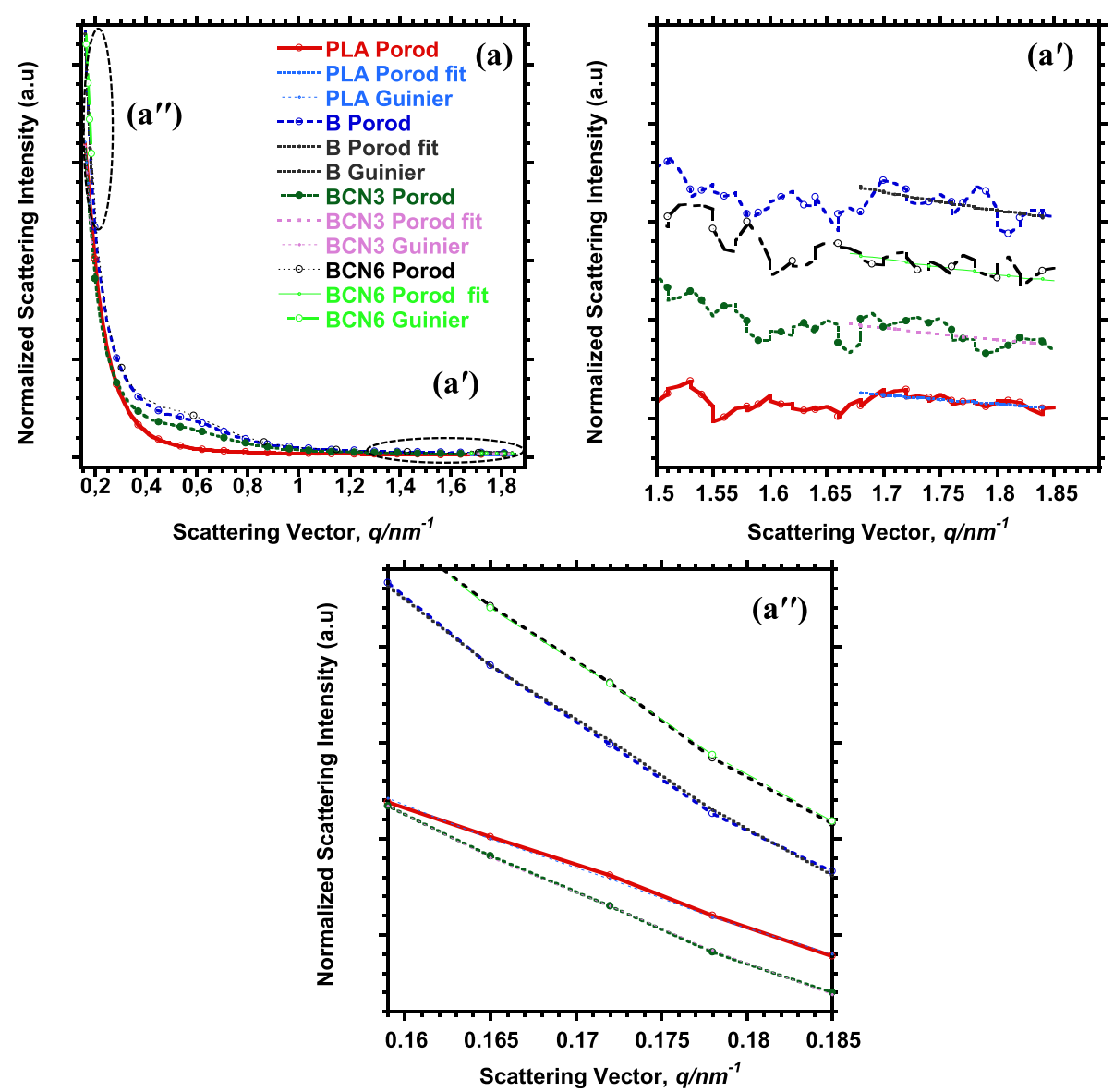

Fig. 3 Normalized scattering intensity plotted against the scattering vector. (a') Zoomed Porod region and Porod fits and (a") Zoomed Guinier region and Guinier fits

respectively [32, 33]. The other less intense peak, which is attributed to (105) plane, is noticed at $22.5^{\circ}$ [32]. In the blend and nanocomposites foam, only the crystalline peaks associated with individual polymers were observed. The $\mathrm{CN}$ diffraction peaks were not observed probably due to low concentrations of $\mathrm{CN}$. The diffraction peaks which could have resulted from fructose entrapped within the 3-dimensional structure of foams were also not observed, and this might also confirm successful leaching of the porogens. The inclusion of $\mathrm{CN}$ particles hampered the crystallization of PLA in the blend, as the intensity of main diffraction peaks at $15.05^{\circ}, 16.8^{\circ}$ and $19.25^{\circ}$ decreased, with respect to PLA and neat blend foam. $\mathrm{CN}$ act as a nucleating agent and thus promote the crystallinity of the polymer. Even so, in this case the $\mathrm{CN}$ particles restricted the crystallization of PLA.

\section{Thermal stabilities}

Figure 5 indicates the thermal stabilities of the prepared foams and $\mathrm{CN}$. CN material is less thermally stable and

Table 3 Morphological properties based on surface area analysis from X-ray scattering

\begin{tabular}{|c|c|c|c|c|c|c|c|}
\hline Sample & $\mathrm{SpV}\left(\mathrm{m}^{2} / \mathrm{cm}^{3}\right)$ & Q-invariant & $\begin{array}{l}\mathrm{Rg}^{\#}(\mathrm{~nm}) \\
\text { Radius of gyration }\end{array}$ & $\left\langle I_{s}\right\rangle(\mu \mathrm{m})$ & $\left\langle I_{p}\right\rangle(\mu \mathrm{m})$ & $\langle(\mu \mathrm{m})$ & $\left\langle I_{G}\right\rangle(\mu \mathrm{m})$ \\
\hline$\overline{P L A}$ & $129.4 \pm 48.91$ & $0.11 \pm 0.02$ & $9.83 \pm 0.16$ & 0.0046 & 0.026 & 0.0039 & 0.0040 \\
\hline B & $120.7 \pm 41.34$ & $0.26 \pm 0.03$ & $11.88 \pm 0.15$ & 0.0050 & 0.028 & 0.0043 & 0.0048 \\
\hline $\mathrm{B}-\mathrm{CN} 3$ & $110.1 \pm 42.38$ & $0.18 \pm 0.02$ & $11.05 \pm 0.08$ & 0.0057 & 0.031 & 0.0048 & 0.0045 \\
\hline $\mathrm{B}-\mathrm{CN} 6$ & $101.9 \pm 8.09$ & $0.28 \pm 0.01$ & $11.02 \pm 0.09$ & 0.0068 & 0.032 & 0.0056 & 0.0046 \\
\hline
\end{tabular}




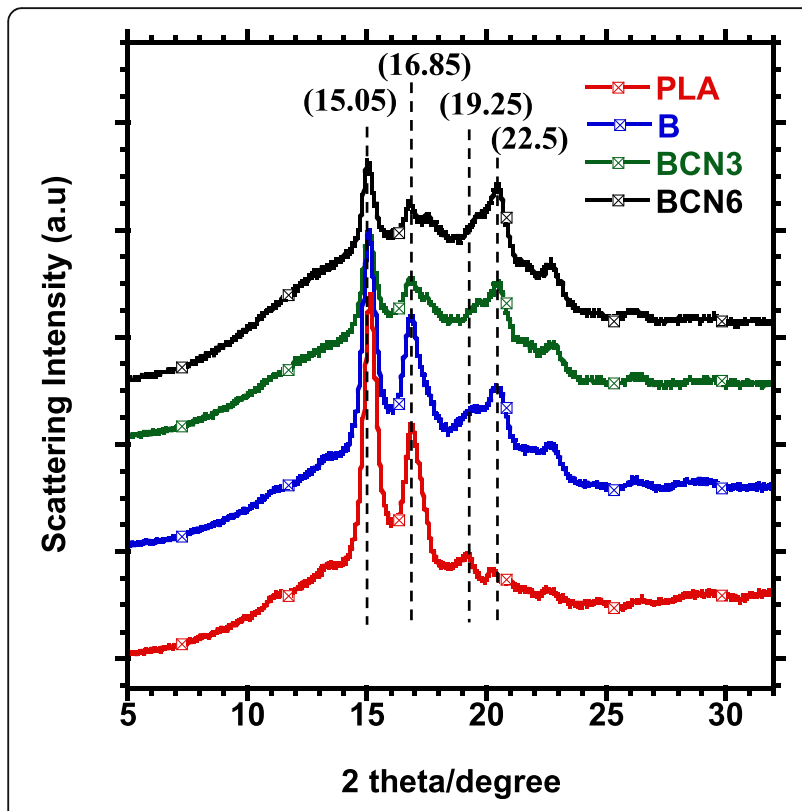

Fig. 4 Crystalline structures of the prepared foams

degrades at lower temperatures $\left(317.4{ }^{\circ} \mathrm{C}\right)$ than both matrices. The thermal degradation behaviour of the prepared foams is discussed at different temperatures; that is, $\mathrm{T}_{10 \%}$ which is taken arbitrarily as onset degradation where $10 \%$ of material degradation has occurred, $\mathrm{T}_{25 \%}$, where $25 \%$ of material degradation has occurred and $\mathrm{T}_{50 \%}$ where $50 \%$ of material degradation has occurred, and lastly, $\mathrm{T}_{\max }$ which is the maximum degradation. PLA shows single degradation step with maximum degradation at $370^{\circ} \mathrm{C}$, while the blend and nanocomposite foams indicate two degradation steps corresponding to individual polymers. Generally, foam materials possess lower properties than unfoamed polymers due to cells, which act as defects in deteriorating the material properties; hence, the thermal degradation, in this case, is explained with reference to both foamed and unfoamed PLA to also examine the effect of cell structure on overall thermal degradation. The $\mathrm{T}_{\text {onset }}$ of neat PLA foam was lower with respect to unfoamed PLA $\left(\mathrm{T}_{10 \%}=\right.$ $342.71 \pm 0.3)$, as expected. The inclusion of both PBSA and $\mathrm{CN}$ showed significant influence on the thermal stability of PLA. The $\mathrm{T}_{\text {onset }}$ has decreased $\left(\sim 4{ }^{\circ} \mathrm{C}\right)$ in the blend foam; however, with $\mathrm{CN}$ addition, the $\mathrm{T}_{\text {onset }}$ increased to higher temperatures, as shown in Fig. 5b. Ojijo et al. [5] observed lower thermal stability of PLA/ PBSA blend, compared to neat polymers. The reduction in $\mathrm{T}_{\text {onset }}$ of PLA in the blend can be attributed to the immiscibility of both matrices. Usually, the thermal stability of foam materials is affected by nanofillers and the cell structure, which mostly affects the onset degradation temperature of the material [34]. The voids in the foamed material act as thermal insulators, restraining heat transfer, and thus increase the $\mathrm{T}_{\text {onset }}[35,36]$. In the current case, an increase in $\mathrm{T}_{\text {onset }}$ of nanocomposite foams is associated with $\mathrm{CN}$ particles, which acted as heat barriers by inhibiting overall heat transfer, which delayed the onset degradation. At $25 \%$ weight loss, thermal stabilities of the nanocomposites also increased with $\mathrm{CN}$ concentration as shown in Fig. 5b. A delay of about $4{ }^{\circ} \mathrm{C}$ was also noticed in the blend, at $50 \%$ weight loss, which can be due to PBSA, which enhanced thermal stability at high temperatures. In the nanocomposites, $\mathrm{CN}$ was still effective in increasing the thermal stability to even higher temperatures than in both PLA and blend

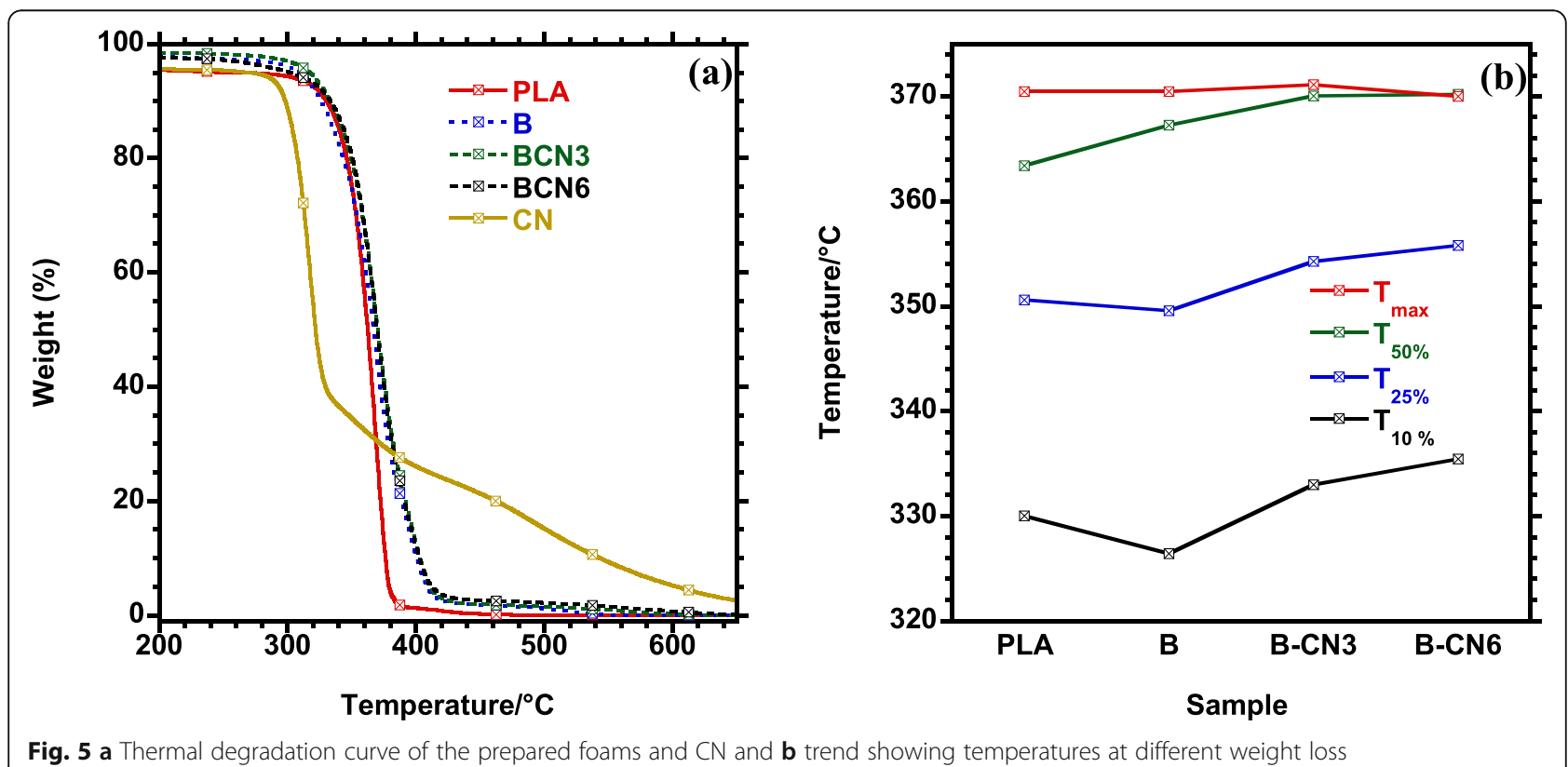


foam. The maximum degradation temperature $\left(\mathrm{T}_{\max }\right)$ of both PLA remained almost the same in all prepared foams. Overall, $\mathrm{CN}$ was effective in delaying the thermal degradation process and enhancing the thermal stability of PLA/PBSA foams at an early degradation stages.

\section{Thermomechanical properties}

The dependence of storage modulus on temperature was used to evaluate the reinforcing effect of $\mathrm{CN}$, as depicted in Fig. 6. PLA is rigid and exhibits high storage modulus compared to its blend counterparts. In this case, the storage modulus is affected by the presence of cells, which reduce the overall stiffness of the material; hence, the storage modulus of PLA has plummeted, especially at low temperatures because of a high number of cells in comparison with other foam materials. Despite its rigidity, the induced crystallinity by solventprocessing has also contributed to high storage modulus, as compared to other foam systems at low temperatures. A rapid decrease in storage modulus was noticed at a temperature range of -52 to $-32{ }^{\circ} \mathrm{C}$. A broad feature observed in this temperature region can be attributed to the $\beta$-relaxation of PLA, which occurs below glass transition temperature $\left(\mathrm{T}_{\mathrm{g}}\right)$, where free volume is minimal [37]. The increased intensity of this relaxation can be attributed to solvent plasticization effect on short-chain segments of PLA such as methyl groups, which are more sensitive to vibrational and/or rotational movements. Further, the addition of ductile PBSA resulted in a rapid decrease in storage modulus as compared to neat PLA foam due to the plasticization effect of PBSA in weakening the PLA chains. Rigid CN particles were effective in increasing the storage

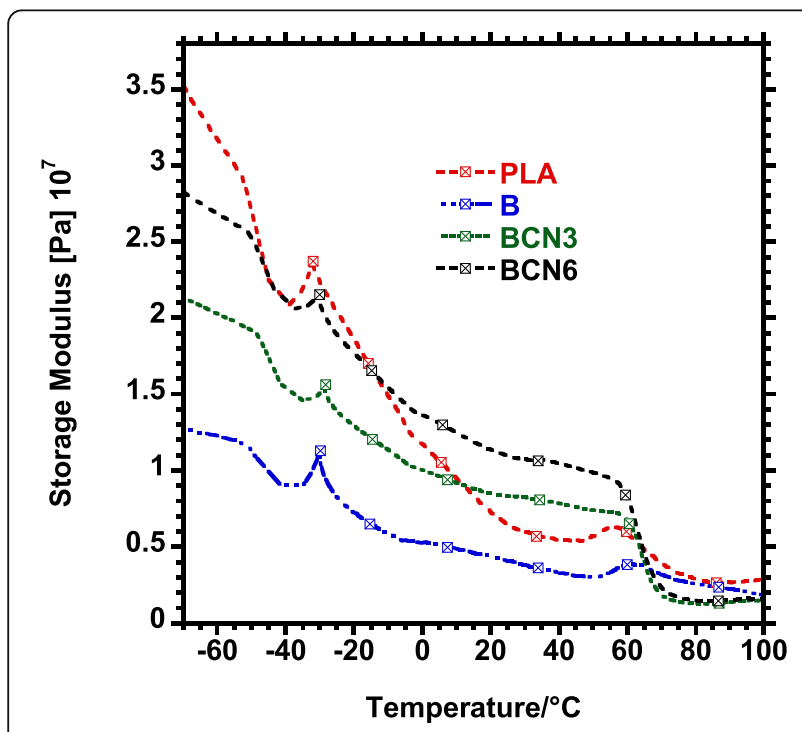

Fig. 6 Storage Modulus curve of the prepared foams modulus in nanocomposite foams even at low temperatures, though the modulus was still lower than neat PLA foam. At higher temperatures (e.g. above $10^{\circ} \mathrm{C}$ ) the modulus of composite foams was much higher as compared to PLA foam. At this stage, irrespective of its rigidness, PLA chains were highly mobile, whereas BCN3 and BCN6 chains were less mobile because of $\mathrm{CN}$ particles, which restricted their mobility at high temperatures. Further, high modulus of nanocomposite foams at high temperatures can also be attributed to the increase in the strut chord, as shown from SAXS analysis. Increase in strut chord results into enhanced stiffness of the material as number of cells decrease and consequently increase the storage modulus, unlike neat PLA foam with high number of cells, which reduces overall stiffness of the material as temperature increases. Table 4 shows a trend in storage modulus at various temperatures, which shows increased modulus with $\mathrm{CN}$ incorporation, whereas blend foam exhibited a very low modulus compared to other foam systems prepared. The increase of the modulus is very relevant in this work. For instance, for poly (vinyl alcohol) (PVA) foams containing microfibrillated cellulose (MFC), at $25^{\circ} \mathrm{C}$ at 3 wt.\% MFC loading the increase of the modulus is only about $20 \%$ with respect to the modulus of neat PVA [38, 39]. In the case of the current investigated systems, by addition of $\mathrm{CN}$, the increase of the storage modulu is much higher. Indeed at $50^{\circ} \mathrm{C}$ the storage modulus containing $3 \mathrm{wt} . \%$ and $6 \mathrm{wt} . \% \mathrm{CN}$ are about 2 and 3 times the storage modulus of the PLA/ PBSA foam. This suggests that $\mathrm{CN}$ is possibly more effective reinforcing agent than MFC in polymer foams.

\section{Conclusion}

Completely bio-based polymer foams with high porosity ('80\%) were successfully prepared through CPL method. The morphological analysis indicated an interconnected open-cell structures in all foams prepared. PBSA was effective in improving the thermal stability of PLA at higher temperatures. Moreover, the blend foam showed a reduction in storage modulus of PLA, suggesting a reduction in brittleness in the presence of PBSA. The CN particles were effective in enhancing the onset degradation of foams. Further, the reinforcing effect of $\mathrm{CN}$ was

Table 4 The storage modulus of the prepared foams at different temperatures

\begin{tabular}{llll}
\hline Sample & $\begin{array}{l}\text { Modulus at }-60^{\circ} \mathrm{C} \\
\left(\times 10^{\mathbf{7}}\right)\end{array}$ & $\begin{array}{l}\text { Modulus at } \mathbf{0}^{\circ} \mathrm{C} \\
\left(\times 10^{\mathbf{7}}\right)\end{array}$ & $\begin{array}{l}\text { Modulus at } 50^{\circ} \mathrm{C} \\
\left(\times 10^{\mathbf{7}}\right)\end{array}$ \\
\hline PLA & 3.16 & 1.16 & 0.56 \\
B & 1.20 & 0.53 & 0.31 \\
BCN3 & 2.02 & 1.00 & 0.73 \\
BCN6 & 2.69 & 1.36 & 0.99 \\
\hline
\end{tabular}


also noticed in bringing the balance in the storage modulus of the prepared foams. However, it will be interesting to also examine the influence of PBSA into the biodegradability of these foams, since it is known to have shorter biodegradation time. Overall, completely biobased polymer foams containing $\mathrm{CN}$ particles were developed. These foams can also be applied in tissue engineering due to their biocompatibility.

\section{Supplementary information}

Supplementary information accompanies this paper at https://doi.org/10. 1186/s42252-020-00011-z.

Additional file 1: Figure S1. Barfoed test for (a) water, (b) fructose solution in water, (c) PLA solution in water, (d) B solution in water, (e) BCN3 solution in water, (f) B-CN6 solution in water. Figure S2. FTIR spectra of PLA and PBSA before after solvent (chloroform) treatment. Figure S3. Surface morphologies of the prepared foams (a) neat PLA, (b) B, (c) B$\mathrm{CN} 3$, (d) B-CN6. Figure S4. Crystalline structures of PLA and PBSA before and after solvent treatment, and Fructose. Figure S5. Crystalline structure of CN.

\section{Abbreviations}

PLA: Polylactide; PBSA: Poly [(butylene succinate)-co-adipate]; CN: Cellulose nanocrystals; CPL: Casting and particulate leaching; PS: Polystyrene; PU: Polyurethane; PVC: Polyvinyl chloride; SEM: Scanning electron microscopy; SAXS: Small-angle X-ray scattering; WAXS: Wide-angle X-ray scattering; DMA: Dynamic mechanical analyzer; TGA: Thermogravimetric analysis; FTIR: Fourier transform infrared spectroscopy; SpV: Surface per volume; $T_{c}$ : Crystallization temperature; $T_{c c}$ : Cold-crystallization temperature; $T_{\mathrm{g}}$ : Glass transition temperature

\section{Acknowledgements}

The authors thank the Department of Science and Innovation (DSI) and the Council for Scientific and Industrial Research (CSIR) for financial support. The authors would also like to thank DSI-CSIR CeNAM characterization facility stuff, and also thank Mr. Rakgoshi Lekalakala and Mr. Mondli Masanabo for their useful contribution. Lastly, the authors thank InnoTech Alberta (Canada) for providing CN material.

\section{Authors' contributions}

Mpho Phillip Motloung and Suprakas Sinha Ray developed the concept. Mpho Phillip Motloung and Simphiwe Zungu performed the experiments. All the authors analyzed the data. Mpho Phillip Motloung wrote the manuscript. Vincent Ojijo and Jayita Bandyopadhyay commented. Suprakas Sinha Ray corrected extensively and edited the manuscript. The author(s) read and approved the final manuscript.

\section{Funding}

The authors would like to thank the Department of Science and Innovation (DSI) (HGER8x) and Council for Scientific and Industrial Research (HGER74p) for financial support.

\section{Availability of data and materials}

All data generated or analysed during this study are included in this study and it supplementary information file.

\section{Competing interests}

The authors declare no conflict of interest.

Received: 28 March 2020 Accepted: 21 September 2020

Published online: 07 October 2020

\section{References}

1. C. Okolieocha, D. Raps, K. Subramaniam, V. Altstädt, Microcellular to nanocellular polymer foams: Progress (2004-2015) and future directions- a review. Eur. Polym. J. 73, 500-519 (2015). https://doi.org/10.1016/j.eurpolymj. 2015.11.001

2. J.-F. Zhang, X. Sun, Biodegradable foams of poly (lactic acid)/starch. I. Extrusion condition and cellular size distribution. J. Appl. Polym. Sci. 106 857-862 (2007). https://doi.org/10.1002/app.26715

3. M. Nofar, C.B. Park, Poly (lactic acid) foaming. Prog. Polym. Sci. 39, 17211741 (2014). https://doi.org/10.1016/j.progpolymsci.2014.04.001

4. N.V. Gama, A. Ferreira, A. Barros-Timmons, Polyurethane foams: Past, present, and future. Materials 11, 1841 (2018). https://doi.org/10.3390/ma11101841

5. V. Ojijo, S.S. Ray, R. Sadiku, Role of specific interfacial area in controlling properties of immiscible blends of biodegradable Polylactide and poly [(butylene succinate)-co-adipate]. ACS Appl. Mater. Interfaces 4, 6690-6701 (2012). https://doi.org/10.1021/am301842e

6. M. Nofar, A. Tabatabaei, H. Sojoudiasli, C.B. Park, P.J. Carreau, M.-C. Heuzey, M.R. Kamal, Mechanical and bead foaming behavior of PLA-PBAT and PLAPBSA blends with different morphologies. Eur. Polym. J. 90, 231-244 (2017). https://doi.org/10.1016/j.eurpolymj.2017.03.031

7. M. Seggiani, V. Gigante, P. Cinelli, M.-B. Coltelli, M. Sandroni, I. Anguillesi, A. Lazzeri, Processing and mechanical performances of poly (butylene succinate-co-adipate) (PBSA) and raw hydrolyzed collagen ( $\mathrm{HC})$ thermoplastic blends. Polym. Test. 77, 105900 (2019). https://doi.org/10. 1016/j.polymertesting.2019.105900

8. M. Salomez, M. George, P. Fabre, F. Touchaleaume, G. Cesar, A. Lajarrige, E. Gastaldi, A comparative study of degradation mechanisms of PHBV and PBSA under laboratory-scale composting conditions. Polym. Degrad. Stab. 167, 102-113 (2019). https://doi.org/10.1016/j.polymdegradstab.2019.06.025

9. T. Han, Z. Xin, Y. Shi, S. Zhao, X. Meng, H. Xu, S. Zhou, Control of thermal degradation of poly (lactic acid) using functional polysilsesquioxane microspheres as chain extenders. J. Appl. Polym. Sci. 132, 41977 (2015). https://doi.org/10.1002/app.41977

10. S. Lee, J.W. Lee, Characterization and processing of biodegradable polymer blends of poly (lactic acid) with poly (butylene succinate adipate). KoreanAust. Rheol. J. 17, 71-77 (2005)

11. V. Ojijo, S.S. Ray, R. Sadiku, Effect of nanoclay loading on the thermal and mechanical properties of biodegradable polylactide/ poly [(butylene succinate)-co-adipate] blend composites. ACS Appl. Mater. Interfaces 4, 2395-2405 (2012). https://doi.org/10.1021/am201850m

12. P. Tiwary, C.B. Park, M. Kontopoulou, Transition from microcellular to nanocellular PLA foams by controlling viscosity, branching and crystallization. Eur. Polym. J. 91, 283-296 (2017). https://doi.org/10.1016/j. eurpolymj.2017.04.010

13. M. Nofar, A. Ameli, C.B. Park, Development of polylactide bead foams with double crystal melting peaks. Polymer 69, 83-94 (2015). https://doi.org/10 1016/j.polymer.2015.05.048

14. S.A. Pradeep, H. Kharbas, L.-S. Turng, A. Avalos, J.G. Lawrence, S. Pilla, Investigation of thermal and thermomechanical properties of biodegradable PLA/PBSA composites processed via supercritical fluid-assisted foam injection molding. Polymers 9, 22 (2017). https://doi.org/10.3390/ polym9010022

15. D. Ray, S. Sain, In situ processing of cellulose nanocomposites. Compos. Part A 83, 19-37 (2016). https://doi.org/10.1016/j.compositesa.2015.09.007

16. N. Lin, Y. Chen, F. Hu, J. Huang, Mechanical reinforcement of cellulose nanocrystals on biodegradability microcellular foams with meltcompounding. Cellulose 22, 2629-2639 (2015). https://doi.org/10.1007/ s10570-015-0684-1

17. R. Avolio, V. Graziano, Y.D.F. Pereira, M. Cocca, G. Gentile, M.E. Errico, V. Ambrogi, M. Avella, Effect of cellulose structure and morphology on the properties of poly (butylene succinate-co-butylene adipate) biocomposites. Crbohydra. Polym. 133, 408-420 (2015). https://doi.org/10.1016/j.carbpol. 2015.06.101

18. M. Cocca, R. Avolio, G. Gentile, E. Di Pace, M.E. Errico, M. Avella, Amorphized cellulose as filler in biocomposites based on poly( $\varepsilon$-caprolactone). Crbohydra. Polym. 118, 170-182 (2015). https://doi.org/10.1016/j.carbpol. 2014.11.024

19. S.S. Borkotoky, P. Dhar, V. Katiyar, Biodegradable poly (lactic acid)/ cellulose nanocrystals (CNCs) composite microcellular foam: Effect of nanofillers on foam cellular morphology, thermal and wettability behavior. Int. J. Biol. Macromol. 106, 433-446 (2018). https://doi.org/10. 1016/j.ijbiomac.2017.08.036

20. J. Reignier, M.A. Huneault, Preparation of interconnected poly $(\varepsilon-$ caprolactone) porous scaffolds by a combination of polymer and salt 
particulate leaching. Polymer 47, 4703-4717 (2006). https://doi.org/10.1016/ j.polymer.2006.04.029

21. A. Sola, J. Bertacchini, D. D'Avella, L. Anselmi, T. Maraldi, S. Marmiroli, M. Messori, Development of solvent-casting particulate leaching (SCPL) polymer scaffolds as improved three-dimensional supports to mimic the bone marrow niche. Mater. Sci. Eng. C 96, 153-165 (2019). https://doi.org/ 10.1016/j.msec.2018.10.086

22. T. Weigel, G. Schinkel, A. Lendlein, Design and preparation of polymeric scaffolds for tissue engineering. Expert Rev. Med. Devices 3, 835-851 (2006). https://doi.org/10.1586/1734440.3.6.835

23. A. Calmark, E. Larsson, E. Malmström, Grafting of cellulose by ring-opening polymerization-a review. Eur. Polym. J. 48, 1646-1659 (2012). https://doi.org/ 10.1016/j.eurpolymj.2012.06.013

24. N. Hu, N. Borkar, D. Kohls, D.W. Schaefer, Characterization of porous materials using combined small-angle X-ray and neutron scattering techniques. J. Membr. Sci. 379, 138-145 (2011). https://doi.org/10.1016/j. memsci.2011.05.053

25. M.l. Elzagheid, Laboratory activities to introduce carbohydrates qualitative analysis to college students. World J. Chem. Educ. 6, 82-86 (2018). https:/ doi.org/10.12691/wjce-6-2-1

26. E. Wiercigroch, E. Szafraniec, K. Czamara, M.Z. Pacia, K. Majzner, K. Kochan, A. Kaczor, M. Baranska, K. Malek, Raman and infrared spectroscopy of carbohydrates: A reviw. Spectrochim. Acta A 185, 317-335 (2017). https:// doi.org/10.1016/j.saa.2017.05.045

27. L. Salvo, G. Martin, M. Suard, A. Marmottant, R. Dendievel, J. Blandin, Processing and structures of solids foams. C. R. Phys. 15, 662-673 (2014). https://doi.org/10.1016/j.crhy.2014.10.006

28. H.-Y. Mi, X. Jing, J. Peng, M.R. Salick, X.-F. Peng, L.-S. Turng, Poly ( $\varepsilon-$ caprolactone) (PCL)/cellulose nano-crystal (CNC) nanocomposites and foams. Cellulose 21, 2727-2741 (2014). https://doi.org/10.1007/s10570-0140327-y

29. M.H. Reich, S.P. Russo, I.K. Snook, H.K. Wagenfeld, The application of SAXS to determine the fractal properties of porous carbon-based materials. J. Colloid Interface Sci. 135, 353-362 (1990). https://doi.org/10.1016/00219898(90)90005-9

30. D.W. Schafer, G. Beaucage, D.A. Loy, K.J. Shea, J.S. Lin, Structure of arylenebridged polysilsesquioxane xerogels and aerogels. Chem. Mater. 16, 14021410 (2004). https://doi.org/10.1021/cm0350683

31. Y. Byun, S. Whiteside, R. Thomas, M. Dharman, J. Hughes, Y.T. Kim, The effect of solvent mixture on the properties of solvent cast polylactic acid (PLA) film. J. Appl. Polym. Sci. 124, 3577-3582 (2012). https://doi.org/10.1002/app. 34071

32. X. Dai, Y. Cao, X. Shi, X. Wang, Non-isothermal crystallization kinetics, thermal degradation behavior and mechanical properties of poly (lactic acid)/MPFs composites prepared by melt-blending method. RSC Adv. 6, 71461-71471 (2016). https://doi.org/10.1039/C6RA14190K

33. W. Wu, C. Wu, H. Peng, Q. Sun, L. Zhou, J. Zhuang, X. Cao, V.A.L. Roy, R.K.Y. $L i$, Effect of nitrogen-doped graphene on morphology and properties of immiscible poly (butylene succinate)/Polylactide blends. Compos. Part B 113, 300-307 (2012). https://doi.org/10.1016/j.compositesb.2017.01.037

34. M. Avella, R. Avolio, I. Bonadies, C. Carfagna, M.E. Errico, G. Gentile, Effect of compatibilization on thermal degradation kinetics of HDPE-based composites containing cellulose reinforcements. J. Therm, Anal. Calorim 102, 975-982 (2010). https://doi.org/10.1007/s10973-010-0836-3

35. M.P. Motloung, V. Ojijo, J. Bandyopadhyay, S.S. Ray, Cellulose nanostructured-based biodegradable nanocomposites foams: A brief overview on the recent advancement and perspectives. Polymers 11, 1270 (2019). https://doi.org/10.3390/polym11081270

36. G. Gedler, M. Antunes, JI. Velasco, Low density polycarbonate-graphene nanocomposites foams produced by supercritical carbon dioxide two-step foaming. Thermal stability. Compos. B Eng. 92, 299-306 (2016). https://doi. org/10.1016/j.compositesb.2016.02.025

37. T.A. Shmool, J.A. Zeitler, Insight into structural dynamics of poly lactic-coglycolic acid at terahertz frequencies. Polym. Chem. 10, 351 (2019). https:// doi.org/10.1039/C8PY01210E

38. M. Avella, M. Cocca, M.E. Errico, G. Gentile, Poly (vinyl alcohol) biodegradable forams containing cellulose fibres. J. Cell. Plast. 48, 459-470 (2012). https://doi.org/10.1177/0021955X12449639

39. G. Gentile, M. Cocca, R. Avolio, M.E. Errico, M. Avella, Effect of microfibrillated cellulose on microstructure and properties of poly (vinyl alcohol) foams. Polymers 10, 813 (2018). https://doi.org/10.3390/polym10080813

\section{Publisher's Note}

Springer Nature remains neutral with regard to jurisdictional claims in published maps and institutional affiliations.

\section{Submit your manuscript to a SpringerOpen ${ }^{\circ}$ journal and benefit from:}

- Convenient online submission

- Rigorous peer review

- Open access: articles freely available online

- High visibility within the field

- Retaining the copyright to your article

Submit your next manuscript at $\boldsymbol{\nabla}$ springeropen.com 